\title{
Coastal gravity field refinement by combining airborne and
}

\section{ground-based data}

\author{
Y. Wu ${ }^{1^{*}, A}$ Abulaitijiang ${ }^{2 *}$,W.E. Featherstone ${ }^{3}$, J.C. McCubbine ${ }^{4}$, O.B. Andersen ${ }^{2}$ \\ ${ }^{I}$ School of Earth Sciences and Engineering, Hohai University, Nanjing, China \\ ${ }^{2}$ DTU Space, Technical University of Denmark, Lyngby, Denmark \\ 3 School of Earth and Planetary Sciences, Curtin University of Technology, GPO Box U1987, Perth, WA 6845, \\ Australia \\ ${ }^{4}$ Geodesy Section, Community Safety and Earth Monitoring Division, Geoscience Australia, Canberra, Australia \\ Correspondence to: YihaoWu (yihaowu@hhu.edu.cn)andAdili Abulaitijiang (adili@space.dtu.dk)
}

\begin{abstract}
Gravity field modelling in coastal region faces challenges due to the degradation of the quality of altimeter data and poor coverage of gravimetric measurements. Airborne gravimetry can provide seamless measurements both onshore and offshore with uniform accuracies, which may alleviate the coastal zone problem. We study the role of airborne data for gravity field recovery in a coastal region, and the possibility to validate coastal gravity field model against recent altimetry data (CryoSat-2, Jason-1, and SARAL/Altika). Moreover, we combine airborne and ground-based gravity data for regional refinement, and quantify and validate the contribution introduced by airborne data. Numerical experiments in the Gippsland Basin over the south-eastern coast of Australia show that the effects introduced by airborne gravity data appear as small-scale patterns on the centimetre scale in terms of quasi-geoid heights. Numerical results demonstrate that the combination of airborne data improves the coastal gravity field, and the recent altimetry data can be potentially used to validate the high-frequency signals introduced by airborne data. The validation against recent altimetry data demonstrates that the combination of airborne measurements improves the coastal quasigeoid, by $\sim 5 \mathrm{~mm}$, compared with a model computed from terrestrial and altimetry-derived gravity anomalies alone. These results show that the recently released altimetry data with relatively denser spatial resolutions and higher accuracies than older altimeter data may be beneficial for gravity field model assessment in coastal areas.
\end{abstract}

Keywords: Coastal gravity field modelling; airborne gravimetry; Jason-1, CryoSat-2, SARAL/Altika data;

This is a post-peer-review, pre-copyedit version of an article published in Journal of Geodesy. The final authenticated version is available online at: http://doi.org/10.1007/s00190-019-01320-3. 


\section{Introduction}

Accurate knowledge of coastal gravity field is of importance for geodetic mean dynamic topography (MDT) modelling, which is useful for studying coastal ecosystem processes and sea level change, as well as facilitating other offshore activities (Pugh and Woodworth 2014; Rio et al. 2011, 2014). Improvements to coastal quasi-geoid/geoid model also facilitate the use of geodetic MDT for height datum unification (Featherstone and Filmer 2012; Filmer and Featherstone 2012; Filmer et al. 2018). However, coastal zones often present multiple challenges for quasi-geoid/geoid recovery (e.g. Hwang et al. 2006; Hirt et al. 2013; Ophaug et al. 2015). First, the satellite altimeter-derived data contain larger errors in coastal zones than in open seas, due to the land and calm water contamination on the return waveforms and degradation of the applied corrections (e.g. atmospheric signals and tides) (Deng and Featherstone 2006; Cipollini et al. 2010; Andersen and Scharroo 2011). The poor data coverage in coastal boundary exacerbates this problem, which remains a barrier on coastal quasi-geoid/geoid determination (e.g. Claessens 2012; Featherstone 2010; Huang 2017). Moreover, inconsistency problems remain among the measurements on land, coastal zone, and open sea, in terms of accuracies and spatial resolutions (e.g. Hipkin et al. 2004; Woodworth et al. 2012; Wu et al. 2017a).

Due to the lack of sufficient data, it is difficult to improve the coastal gravity field in terms of accuracy and reliability, especially in narrow and shallow water areas, where marine surveys are almost inaccessible (e.g. Olesen et al. 2000; Forsberg et al. 2012a; Jekeli et al. 2013). This coastal zone problem may be allayed with the use of airborne gravimetric survey, which fills the data gap in this area (e.g. Schwarz and Li 1996; Forsberg et al. 2000; Olesen et al. 2002; Barzaghi et al. 2009). The airborne survey supplies seamless gravity measurements over land and sea with uniform accuracies, which is valuable for coastal gravity field modelling (e.g. Forsberg and Kenyon 1995; Andersen and Knudsen 2000; Fernandes et al. 2000; Forsberg et al. 2001, 2012b). Previous investigations showed that airborne measurements had great potential in coastal gravity field refinement (e.g. Kearsley et al. 1998; Bastos et al. 2000; Olesen 2003; Hwang et al. 2006), however, the lack of control data remains a problem for validating the additional signals introduced by airborne data (e.g. McCubbine et al. 2018).

On the other hand, the recent satellite altimetry missions (e.g. CryoSat-2, Jason, and SARAL/Altika) provide much denser and more accurate sea surface heights (SSHs) than traditional radar altimetry ones (e.g. Geosat and ERS-1) (e.g. Sandwell et al. 2013, 2014; Garcia et al. 2014; Verron et al. 2015). In particular, the CryoSat-2 mission with Synthetic Aperature Radar (SAR) and SAR interferometric (SARIn) measurements provides accurate SSH data up to several kilometres from the coast (e.g. Abulaitijiang et al. 2015; Passaro et al. 2016; Bonnefond et al. 2018). As a result, the coastal geodetic MDTs derived from these data approximately agree at several centimetres level with the ocean models and tide gauge-derived MDT data (Ophaug et al. 2015; Idžanović et al. 2017; Andersen et al. 2018). This shows that recent altimetry data may serve as an additional source for coastal gravity field and MDT modelling and validation. Thus, the aim of this study is twofold: first, to investigate the possibility to validate the coastal quasi-geoid/geoid models against recent altimetry data; second, to combine airborne gravity data and heterogeneous terrestrial gravimetry and altimetry measurements for regional quasi-geoid/geoid refinement, and quantify and validate the contribution introduced by airborne data.

\section{Study area and data}

The study area is located over the Gippsland Basin along the south-eastern coast of Victoria in Australia, where a high-resolution airborne gravimetric survey was contracted by the Victoria State Department of Primary Industries as part of studies for a carbon capture and storage project (Martin et al. 2011), see Figure 1. This airborne survey covers both onshore and offshore areas, so provides reasonable data coverage for coastal gravity field refinement, see the blue lines in Figure 1. Besides, surface gravity data are available, derived from the recent land measurements over the mainland of Australia and newly released satellite altimetryderived gravity anomalies 
(Featherstone et al. 2018a), see the red dots in Figure 1. Shipborne gravity measurements are excluded since they are sparse and unreliable (Featherstone 2009).

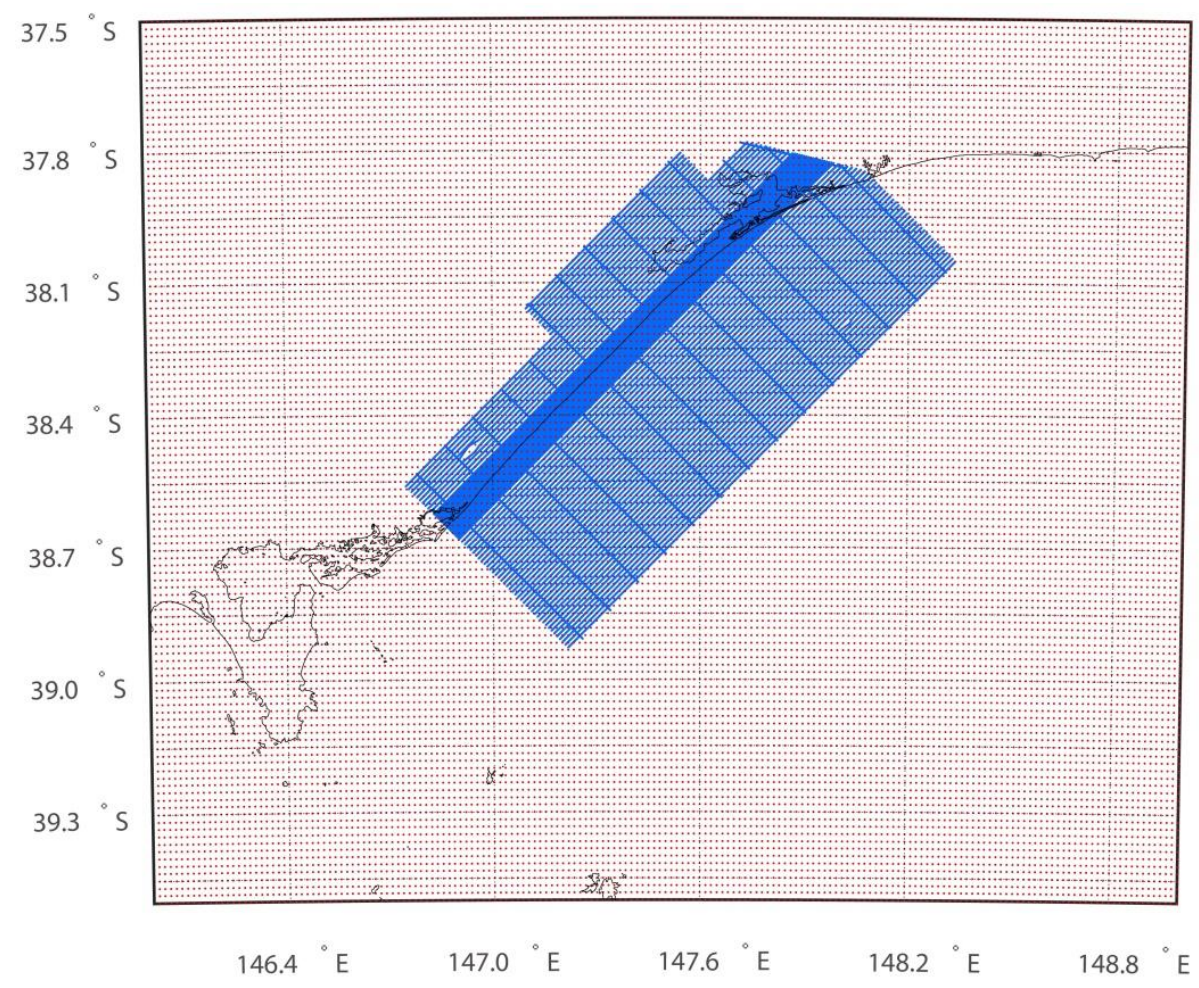

Figure 1 Study area and the distribution of gravity data. The blue lines represent the airborne flight lines, and the red dots show the gridded surface gravity data, i.e., the terrestrial gravity data in land and altimetry-derived gravity data in ocean

\subsection{Surface gravity anomalies}

Terrestrial gravity data used in this study are consistent with that used for computing the recent Australian gravimetric quasigeoid 2017 (AGQG2017), where the additional 280,000 land gravity observations were incorporated, compared with the data used for computing AGQG2009 (Featherstone et al. 2018a). Marine gravity data were extracted from the recently released retracked altimetry gravity anomalies (include Jason-1 and CryoSat-2 data), which were computed by the Scripps Institution of Oceanography (University of California) (Sandwell et al. 2014). These gravity data improved the marine gravity field derived from the older altimeter data (e.g. Geosat and ERS-1), by a factor of 2 4 (Sandwell et al. 2013, 2014). The altimetry-derived gravity data are generally accurate to several $\mathrm{mGal}$ in open oceans; while, this value may decrease to tens of $\mathrm{mGal}$ in coastal regions (Sandwell et al. 2014). Land gravity data and altimetry-derived gravity anomalies were merged through the procedures discussed in Featherstone et al. (2011), and the merged grid has a spatial resolution of $1^{\prime} \times 1^{\prime}$

\subsection{Airborne gravity measurements}

An airborne gravimetric survey was conducted by Sander Geophysics Limited (SGL) during November and December 2011 using the Airborne Inertially Referenced Gravimeter (AIRGrav) system. This survey area composed of approximately $1 / 3$ onshore area and $2 / 3$ offshore area. This survey contained 11 flights in total to complete 10523 line kilometres. The traverse lines were northeast-southwest oriented and spaced at 1 $\mathrm{km}$, and a nine $\mathrm{km}$ wide strip along the coast was flown at $500 \mathrm{~m}$ line spacing; while the tie lines were northwestsoutheast 
oriented and spaced at $10 \mathrm{~km}$. The flight heights ranged from 143 to $362 \mathrm{~m}$ above the mean sea level, with an average velocity of approximately $55 \mathrm{~m} / \mathrm{s}$ (Martin et al. 2011).

Gravity anomalies were calculated by subtracting the GPS-derived aircraft accelerations from the inertial accelerations, and corrected for the Eötvös effect. The normal gravity values were removed, and the data were provided at a sample rate of $2 \mathrm{~Hz}$. Off-level corrections were applied to compensate for the instrument tilt, and high-frequency noises were reduced by applying a $35 \mathrm{~s}$ half-wavelength cosine tapered lowpass filter (Martin et al. 2011). The gravity data were referenced to the existing Australian Absolute Gravity Datum 2007 (AAGD07) (Tracey et al. 2007), and the geodetic coordinates were referenced to the GRS80 reference ellipsoid and Geocentric Datum of Australia 1994 (GDA94). The ellipsoidal heights were converted to heights above the Australian Height Datum (AHD) using AUSGeoid09, which is a hybrid gravimetric-geometric model (Featherstone et al. 2011). Nine repeat lines were conducted for quality control, and the overall standard deviation (SD) of the variations of repeat lines was estimated as $0.36 \mathrm{mGal}$. Moreover, the SD of the differences between measured gravity values at the intersections of tie and traverse lines was computed as $0.35 \mathrm{mGal}$, which was commensurate with the statistics of the repeat lines (Martin et al. 2011). These airborne gravity data were not used in the recently computed Australian gravimetric quasigeoid 2017 (AGQG2017) (Featherstone et al. 2018a).

\subsection{Satellite altimetry data}

The altimeter-derived data are used to assess the coastal gravity field models and validate the additional signals introduced by airborne data. The altimetry data are extracted from Radar Altimeter Database System (RADS, Scharroo et al. 2013) and include seven and half years (2010-2017) of CryoSat-2 data, one full 406day repeat cycle of Jason-1 geodetic mission data and one year of SARAL/Altika drifting phase data. Cryosat-2 operated in the low resolution mode (LRM) in this study area, which was identical to the conventional altimeters such as Jason-1. The altimeters on CryoSat-2 and Jason-1 operated in the Ku-band, while it was operating in the Ka-band for SARAL/Altika. Ka-band radar altimeter was proved to give better range precision compared with Ku-band altimeter (Smith 2015; Zhang and Sandwell 2017).

In RADS, $1 \mathrm{~Hz}$ observations were derived from the elementary $20 \mathrm{~Hz}$ (40 Hz for SARAL) measurements. Each of the altimetry waveform was retracked using the modified Brown retracker (Brown 1997). Contaminated waveforms near the coastal zone that were hard to fit an analytical waveform were discarded and not used for the derivation of $1 \mathrm{~Hz}$ observations. For CryoSat-2 and Jason-1, at least 16 of the $20 \mathrm{~Hz}$ observations were used to obtain a $1 \mathrm{~Hz}$ observation. For SARAL, at least 33 of the $40 \mathrm{~Hz}$ observations were used to produce a $1 \mathrm{~Hz}$ observation. In addition, range biases between satellites were corrected in RADS. Therefore, the altimetry data obtained from RADS are reliable and of high quality near the coastal zone, although there may be data gaps close to the coastal lines. In the process of deriving the $1 \mathrm{~Hz}$ observation, the standard deviation of the inconsistencies between the finally computed $1 \mathrm{~Hz}$ observation and original observations provides the estimated error information of altimeter data. The maximum/minimum value of the estimated errors of these data over the local region (the distribution of altimeter data is shown in Figure 2) is $8 / 0.6 \mathrm{~cm}$, with a mean magnitude of $4.6 \mathrm{~cm}$.

In this study, the altimeter-derived quasi-geoid heights are computed for validation purpose. It is worth to mention that we focus on the short wavelength features of local gravity field. Hence, after retrieving the sea surface heights (SSH) from RADS, the EGM2008 quasi-geoid (Pavlis et al. 2012, 2013) up to degree and order (d/o) 1080 and the full dynamic topography signals from the EGM2008 Dynamic Ocean Topography (DOT, or known as mean dynamic topography (MDT)) model (d/o 180) are removed from the SSHs to derive the residual geometric quasi-geoid heights. It is noticeable that oceanic MDT may be used instead of geodetic MDT to derive independent quasi-geoid heights. However, the focus of this study is on the validation of local gravity field at short wavelengths $(<20 \mathrm{~km})$, while the commonly used MDTs have relatively low resolutions and mainly reflect 
the spectral contents at longer wavelengths. Thus, the choices of MDTs may have less impact on the validation results. Besides, another reason for using EGM2008 DOT is to be consistent with what has been removed at long wavelengths, i.e., EGM2008 up to d/o 1080 is removed. In this way, the spectral consistency of reference model and MDT used for data pre-processing is ensured, and aliasing problem may be avoided. Further, the data are reduced by the residual terrain model (RTM) corrections (Forsberg and Tscherning 1981; Forsberg 1984), though they are quite small over the local area. Then, the crossover adjustment is applied to reduce the tilts and biases in the geometric quasi-geoid heights. The outliers in the data are removed based on the 3 -sigma rule. Finally, a Gaussian filter with a correlation length of $3 \mathrm{~km}$ is applied to reduce the high-frequency noises. The residual altimeter-derived quasi-geoid heights are shown in Figure 2, which range from -8.4 to $8.5 \mathrm{~cm}$, with a standard deviation of $2.65 \mathrm{~cm}$. The mean value of these data is approximately $0.6 \mathrm{~mm}$, which indicates the tilts and biases are successfully removed.

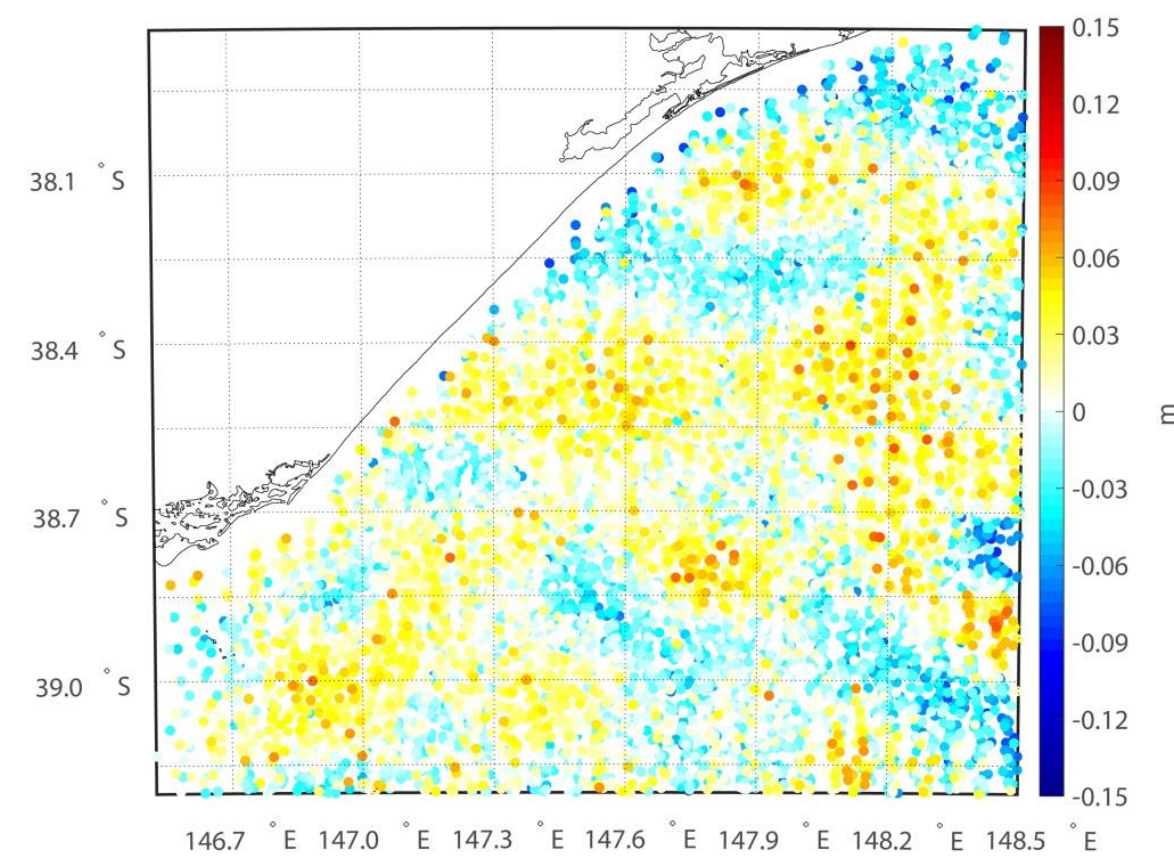

Figure 2 Residual geometric quasi-geoid heights derived from CryoSat-2, Jason-1, and SARAL/Altika data. Note that EGM2008 up to d/o 1080 and RTM effects are removed

\section{Data preparation}

\subsection{Terrain effects}

Coastal gravity field is recovered within the framework of remove-compute-restore (RCR) methodology (Sjöberg 2005; Omang and Forsberg 2000), where a global geopotential model (GGM) and terrain effects are removed from the surface and airborne gravity data to decrease the signal correlation length and smooth the local gravity signals. Following Featherstone et al. (2018a), EGM2008 is selected as the reference model, and we truncate the d/o of this model to 1080. RTM is applied for recovering the signals that have the shorter wavelengths than the mean distance between the measured gravity data. SRTM (Shuttle Radar Topography Missions) and GEBCO (General Bathymetric Chart of the Oceans) are combined to derive a uniform digital terrain model (DTM) with a spatial resolutionf $3 " \times 3 "$ overland and sea,seEigure 3 (a). A moving average filter with a window width of approximately $18.33 \mathrm{~km}$ is applied to the combined DTM to derive the mean elevation surface (MES) for RTM reduction. In this manner, the constructed MES (Figure 3 (b)) is in agreement with the spherical degree of the adopted GGM (Hirt 2010). Tesseroids are chosen instead of prisms as the integral elements considering the 
curvature of the earth (Heck and Seitz 2007). Figure 4 shows the point-wise residual gravity anomalies at the altitude of airborne survey, and the introduction of RTM reduction more significantly reduces the high-frequency signals in land than in ocean. We observe smoothness in the northeast parts of ocean, see the red signals around $\left(147.9^{\circ} \mathrm{E}, 38.1^{\circ} \mathrm{S}\right)$, while in other regions the incorporation of RTM corrections does not significantly smooth the local gravity field (even intensify the local signals, e.g. see the blue signals in the southwest parts around $\left(147.1^{\circ}\right.$ E, $\left.38.6^{\circ} \mathrm{S}\right)$ ). From the statistics, we can hardly see significant differences, where the SD of residual data changes from 3.5 to $3.4 \mathrm{mGal}$ with RTM reductions. This may be attributed to the poor quality and low resolution of the bathymetry model as well as the relatively flat local bathymetry.

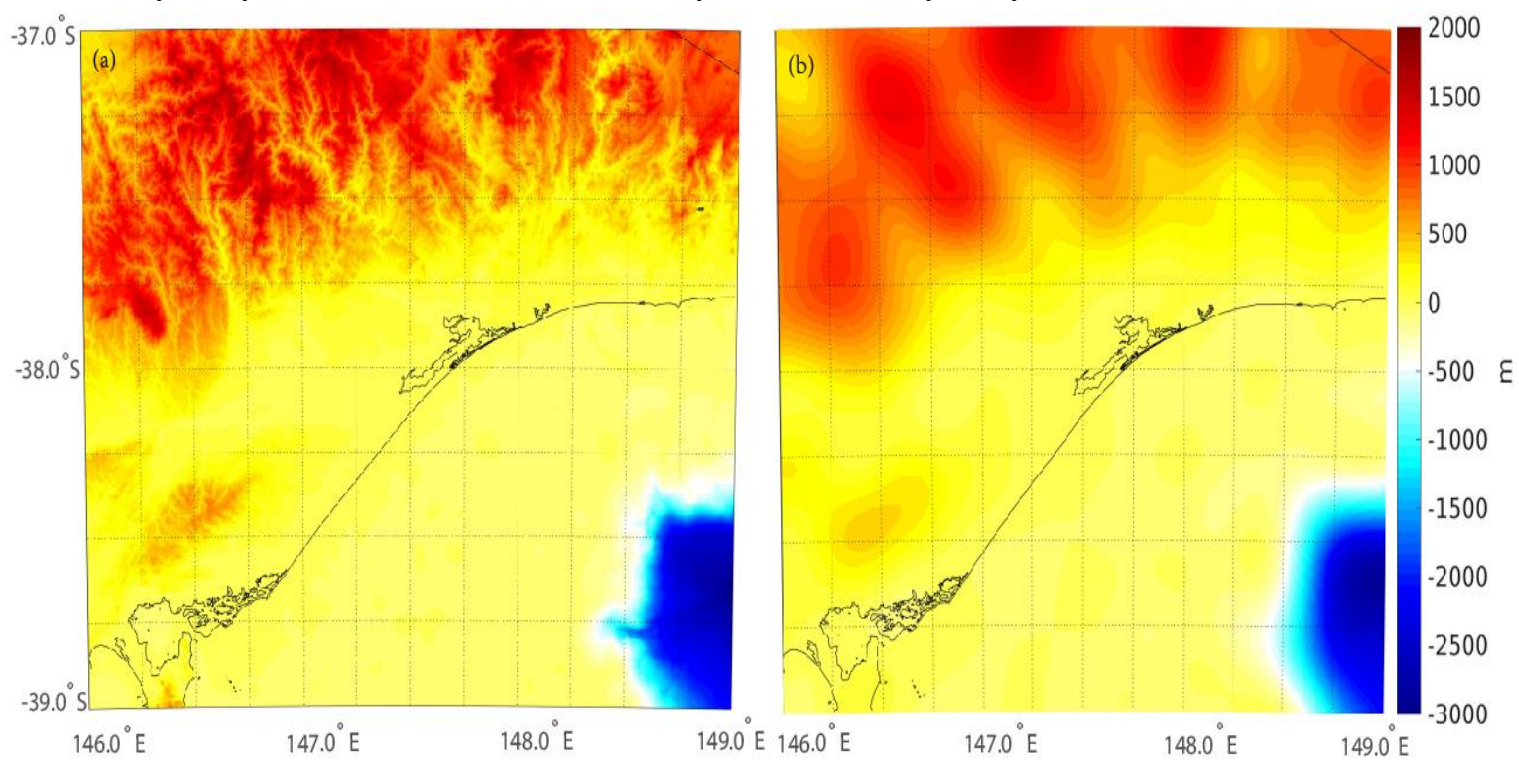

Figure 3 Digital terrain model (a) and mean elevation surface (b) over the Gippsland Basin
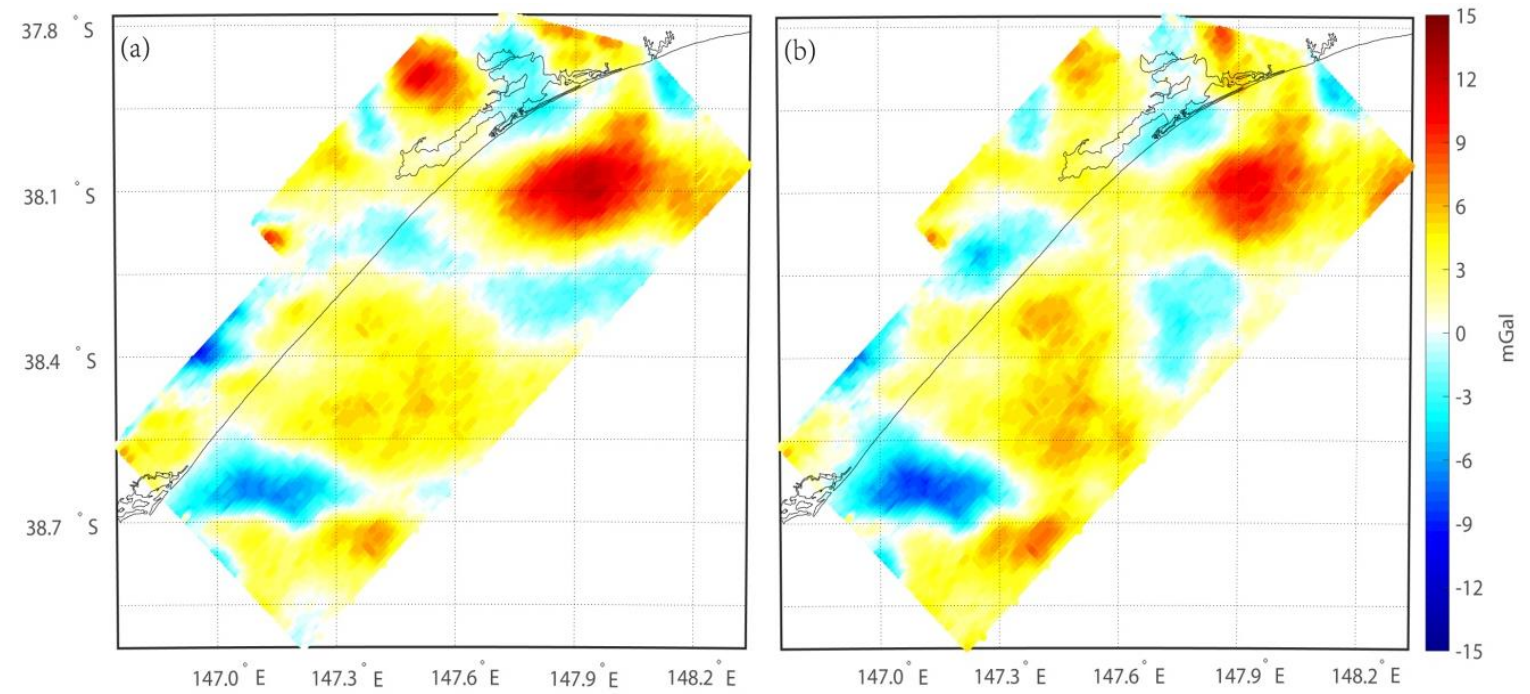

Figure 4 Residual point-wise airborne gravity anomalies. The left and right figures represent data without and with RTM corrections, respectively. EGM2008 up to d/o 1080 has been removed

\subsection{Data combination}

The airborne observations and surface gravity data are located at different altitudes with heterogeneous spatial coverage and resolutions; thus, prior to gravity field modelling, we need to downward continue (DWC) airborne data to the quasi-geoid and merge them with the ground-based measurements to derive data with a uniform spatial resolution. Following Mccubbine et al. (2018), we use the three-dimensional least squares collocation (LSC) with 
the logarithmic covariance function for DWC, since it can downward continue airborne measurements and merge them with ground-based data in a single step (e.g. Forsberg 1987, 2002). For DWC, the Bouguer gravity anomaly is chosen for interpolation (Amos and Featherstone 2004), and the residual gravity data are derived by subtracting the GGM components and RTM effects, which are used for computing the empirical spatial covariance. Different data are assumed to be independent, and the scaled diagonal matrices are used to design the full variance-covariance matrix of LSC model. The detailed procedures for DWC and data merging can be referred to Mccubbine et al. (2018).

The merged grid with the airborne, terrestrial and altimetry gravity data is shown in Figure 5 (a), which maps the local gravity field with a spatial resolution of $1^{\prime} \times 1^{\prime}$. To investigate the contribution of airborne data to the merged gravity anomalies, we also implement the LSC interpolation procedures to derive the grid without the airborne gravity data, see Figure 5 (b). Figure 6 shows the difference between the gridded data computed with and without the airborne data, indicating the contribution of airborne data. The additional signals introduced from the airborne data reach a level of roughly $10 \mathrm{mGal}$, with a SD of $1.3 \mathrm{mGal}$, displaying more significant signals in coastal areas than in onshore areas. Possible reason may be due to the degradation of quality of altimetry data in coastal areas, whereas airborne gravimetry does not suffers from the coastal zone problem, and may provide more accurate gravity field information than altimeter data. On the other hand, the recently surveyed terrestrial gravity data are of high quality and cover onshore regions over the Gippsland Basin, and the additional signals introduced by the airborne data become less significant in land.
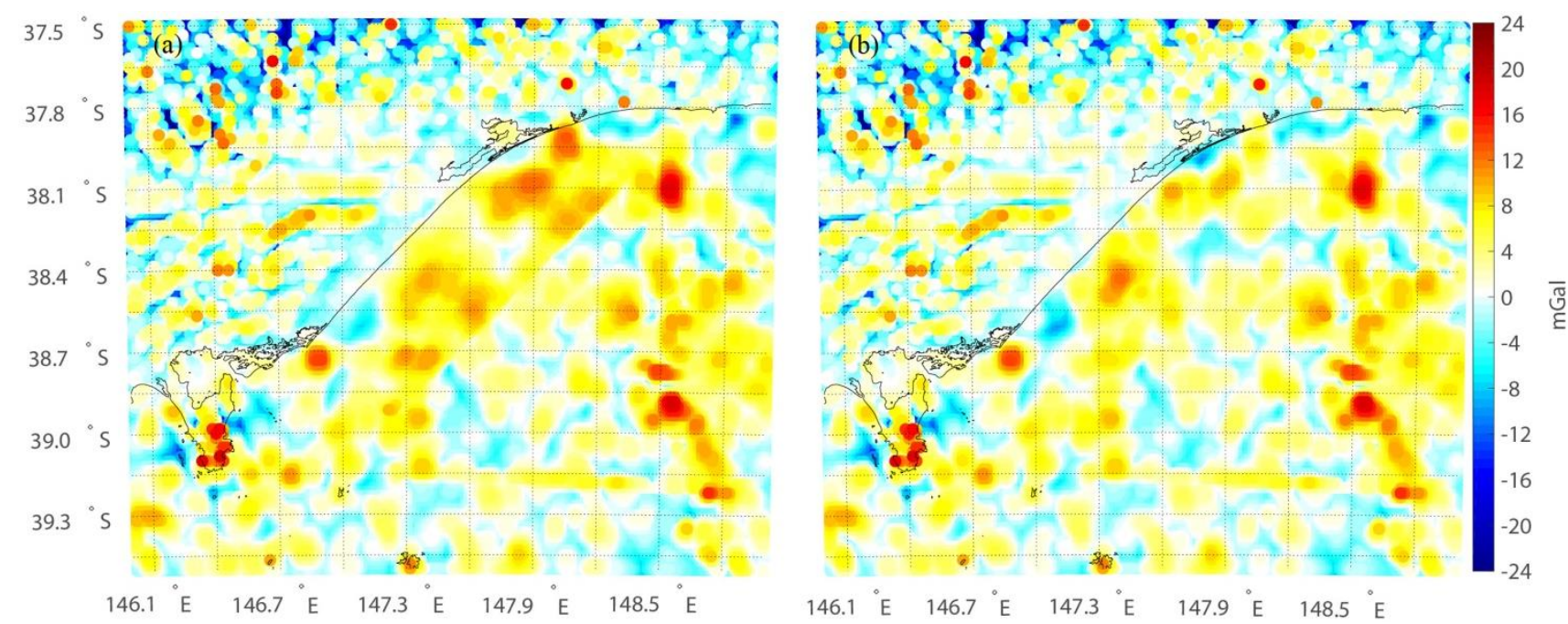

Figure 5 Merged gravity anomalies (a) with and (b) without airborne gravity data. Note that EGM2008-derived gravity anomalies up to d/o 1080 and RTM corrections are removed 
Figure 6 Difference between the merged data with and without airborne gravity data

\section{Results and discussions}

\subsection{Regional quasi-geoids modelling}

We parameterize the coastal gravity field with Poisson wavelets, which are radially symmetric basis functions that have localizing properties both in the spatial and frequency domains; and they have been widely used for local gravity field modelling (e.g. Chambodut et al. 2005; Schmidt et al. 2006; Panet et al. 2011). The full definition of Poisson wavelet can be seen in, e.g. Holschneider et al. (2003, 2007) and Wittwer (2009). The method for gravity field recovery from Poisson wavelets can be referred to, e.g. Klees et al. (2008) and Wu et al. (2017b). The order of Poisson wavelets is fixed at three to achieve a balance between fitting the data and obtaining a smooth solution (Chambodut et al. 2005; Panet et al. 2011). The target region extends from $37.5^{\circ} \mathrm{S}$ to $39.5^{\circ} \mathrm{S}$ latitude and $146^{\circ} \mathrm{E}$ to $149^{\circ} \mathrm{E}$ longitude. We place the Poisson wavelets on a Fibonacci grid on a surface under the topography and keep it parallel with the topography (Tenzer and Klees 2008). The mean distance between Poisson wavelets is chosen as $2.5 \mathrm{~km}$, and the depth of the grid is fixed as $5 \mathrm{~km}$. Since the regional solution derived from Poisson wavelets suffers from the edge effects, the boundary limits of the target area are contracted by $0.25^{\circ}$ in all the directions to extract the effective signals. Due to the heterogeneous spatial resolutions and noise properties of different data as well as the inappropriate network design of Poisson wavelets (i.e., the depth and number of Poisson wavelets), the associated normal matrix may become highly ill-conditioned (Wittwer 2009; Panet et al. 2011). The first-order Tikhonov regularization is used to tackle the ill-conditioned problem (Kusche and Klees 2002), and the convergent regularization parameter is estimated by using the Monte-Carlo variance component estimation (MCVCE) method (Koch and Kusche 2002; Kusche 2003). Details of regularization parameter estimation can be referred to $\mathrm{Wu}$ et al. (2018).

In order to quantify the contribution of airborne gravity data, we compute two regional solutions; the first one is modelled with the merged grid with the airborne gravity data (Figure 5 (a)), which is denoted as QGland_TSA (gravimetric quasi-geoid over the Gippsland Basin modelled with terrestrial (T), satellite altimetry (S), and airborne (A) gravity data). While, the solution modelled only with the surface gravity data (Figure 5 (b)) is denoted as QGland_TS. The difference between QGland_TSA and QGland_TS shows the contribution of airborne gravity data in terms of quasi-geoid heights, see Figure 7. These additional signals stemmed from airborne data 
display as small-scale features on the centimetre scale, which mainly locate in coastal regions. This is consistent with the results from, e.g. Forsberg et al. (2012a) and McCubbine et al. (2018). These results show that the airborne data contain signals that cannot be resolved from the surface gravity data alone, which may contribute to local gravity field recovery. Moreover, we observe more significant signals occurring in coastal areas than in land, and the possible reason may be due to the degradation of quality of altimetry gravity anomalies in coastal areas.

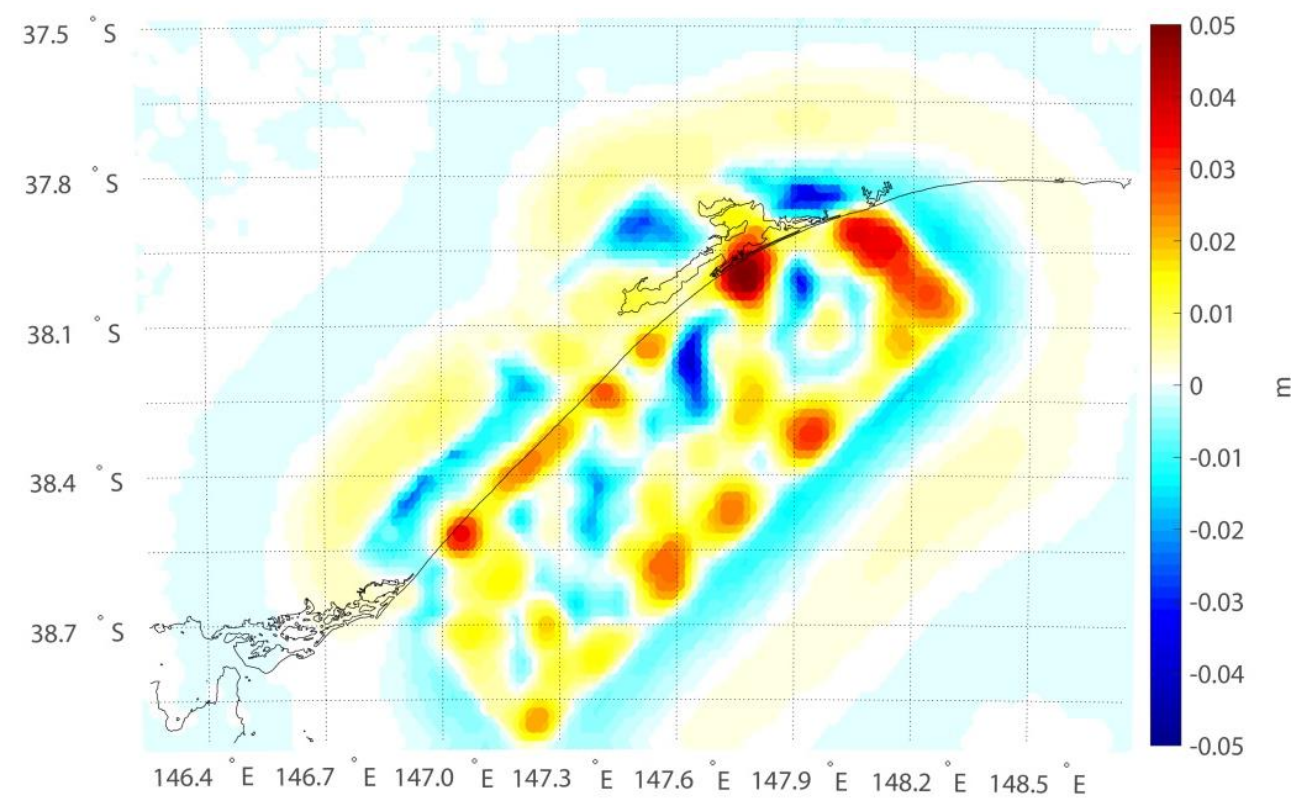

Figure 7 Contribution of airborne gravity data to local gravimetric quasi-geoid, i.e., the difference between the solutions modelled from the merged data with and without airborne gravity data

\subsection{Validation and comparison}

\subsubsection{Validation against GPS/levelling data}

Local GPS/levelling data are firstly introduced for model validation and comparison, and the detailed information of local GPS/levelling data can be referred to Featherstone et al. (2018b). The original GPS/levelling data were referred to the Australia Height Datum (AHD) (Roelse et al. 1971). However, AHD is known to contain systematic errors, where a north-south tilt and regional distortions exist (Featherstone and Filmer, 2012). Thus, heights from readjustments of the Australia National Levelling Network (ANLN) were implemented, which served as an updated version of the levelling data used in 1971 AHD adjustment (Featherstone et al. 2018a). Heights derived from a least square adjustment of ANLN are used, which were corrected for the MDT, derived from the Commonwealth Scientific and Industrial Research Organisation Atlas of Regional Seas 2009 (CARS2009) (Dunn and Ridgway 2002; Ridgway et al. 2002). These data are suitable for quasi-geoid assessment in Australia (Featherstone et al. 2018a).

Validation results with local GPS/levelling data are shown in Figure 8 and Table 1. Note that we removed the mean values of the misfit between the gravimetric models (both for regional models and GGMs) and local GPS/ levelling data. These models deviate from the local GPS/levelling data by tens of centimetres in this area, due to the commission errors of the GGMs and uncorrected systematic errors in gravity data and height systems. Thus, if the mean biases are not removed, the inconsistencies between these models and GPS/levelling data are dominated by the systematic errors, which are undesirable for model comparison. The validation results with GPS/levelling data can hardly demonstrate the contribution of airborne data, and the possible reasons are twofold. First, the GPS/levelling data are sparsely distributed in onshore areas, consequently, the high-frequency signals introduced by airborne data can be hardly detected by the GPS/levelling data. Moreover, we observe most 
significant signals concentrate in coastal regions (Figure 7), e.g. see the red signals in south of Rotamah Island around $\left(147.8^{\circ} \mathrm{E}, 38.0^{\circ} \mathrm{S}\right)$ and blue ones located around $\left(147.65^{\circ} \mathrm{E}, 38.2^{\circ} \mathrm{S}\right)$; while less significant signals are observed in onshore areas. We notice that the terrestrial gravity data used for computing AGQG2017 have good spatial coverage in onshore areas over the Gippsland Basin (Featherstone et al. 2018a). As a result, terrestrial data alone may be sufficient for local small-scale signals recovery in land, and the contribution from airborne data may become less significant. Existing models are introduced for further comparisons, namely AGQG2017 and five high-order GGMs, i.e., EGM2008, and EIGEN-6C4 (d/o 2190) (Förste et al. 2014), GECO (d/o 2190) (Gilardoni et al. 2015), SGG-UGM-1 (d/o 2159) (Liang et al. 2018), and GOCO05c (d/o 720) (Fecher et al. 2017). The statistics in Table 1 show that most gravimetric quasi-geoid models except GOCO05c show comparable accuracies, i.e., approximately between $9.7 \mathrm{~cm}$ and $10.4 \mathrm{~cm}$. Due to the limited accuracy of local GPS/levelling data, these models cannot be discriminated (Featherstone et al. 2018a, b). The accuracy of GOCO05c decreases by approximately $3 \mathrm{~cm}$ compared with other models, and this may be due to the unrecovered small-scale signals of this model, since the full d/o of GOCO05c is truncated to 720 .
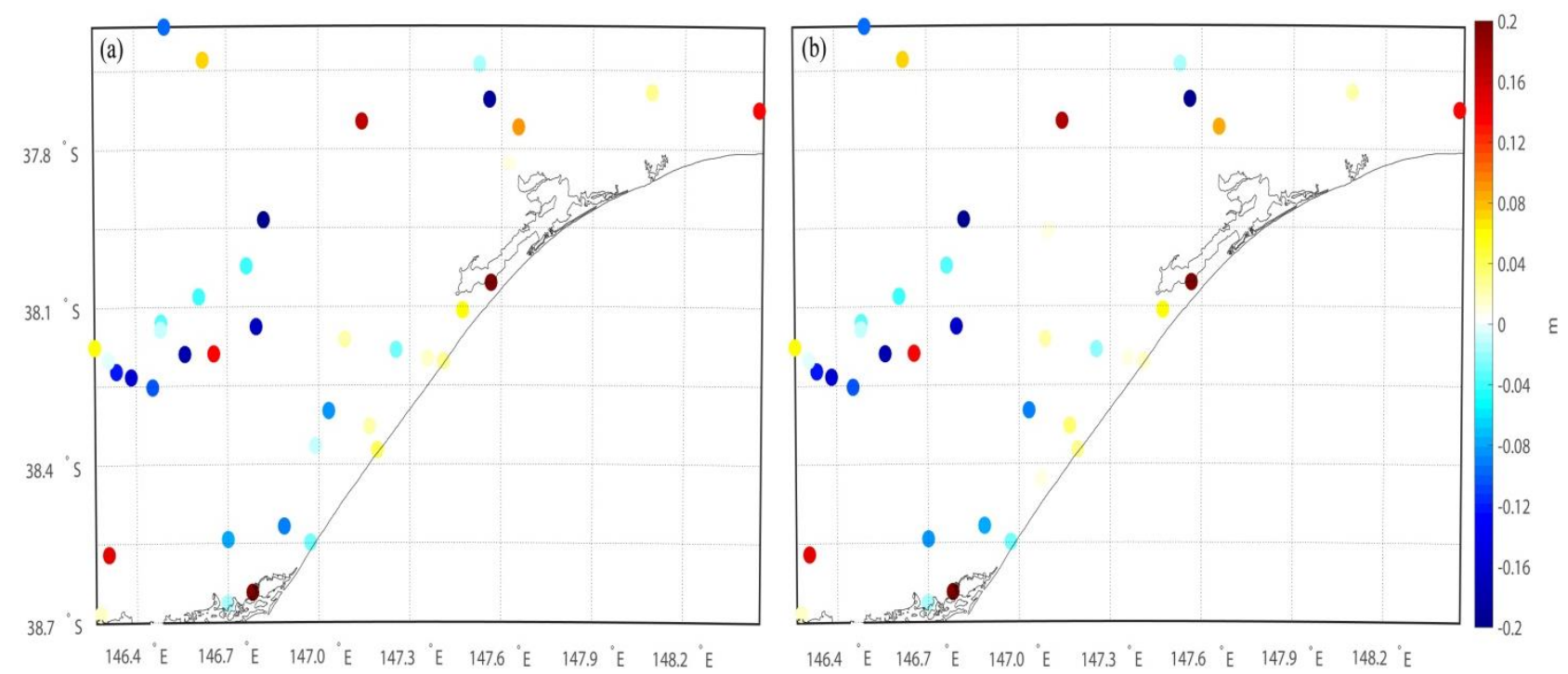

Figure 8 Validations of (a) QGland_TS and (b) QGland_TSA against CARS2009-constrainted GPS/levelling data. Note that the mean value of the misfit between QGland_TS/QGland_TSA and GPS/levelling data is removed

Table 1 Statistics of evaluations of different gravimetric quasi-geoids using CARS2009-constrainted GPS/levelling data (units: m). Note that the mean values of the misfit between different gravimetric quasi-geoid models and GPS/levelling data are removed

\begin{tabular}{llll}
\hline & Max & Min & SD \\
\hline QGland_TSA & 0.206 & -0.193 & 0.096 \\
QGland_TS & 0.213 & -0.200 & 0.097 \\
AGQG2017 & 0.342 & -0.219 & 0.103 \\
EGM2008 & 0.346 & -0.192 & 0.104 \\
EIGEN-6C4 & 0.329 & -0.169 & 0.098 \\
GECO & 0.296 & -0.200 & 0.099 \\
SGG-UGM-1 & 0.304 & -0.172 & 0.098 \\
GOCO05c & 0.437 & -0.309 & 0.132 \\
\hline
\end{tabular}

\subsubsection{Validation against altimeter-derived data}

The satellite altimeter-derived quasi-geoid heights can be used to assess the performance of quasi-geoid model in 
oceanic areas, e.g. see Lieb et al. (2016). The validation of coastal gravity field using altimeter-derived data may be more challenging than that in open seas, since the quality of satellite altimetry data is typically suspicious close to coast. However, the recent altimetry data are denser and more accurate than the traditional data, which may be used as the validation data in coastal areas. The additional signals introduced from airborne data are validated against the CryoSat-2, Jason-1 and SARAL/Altika data, where only the signals located inside the airborne survey are assessed, and 1701 point-wise altimeter-derived quasi-geoid heights are used. The maximum/ minimum value of the estimated errors of these 1701 point-wise altimetry data is $7 / 1 \mathrm{~cm}$, with a mean magnitude of $3.9 \mathrm{~cm}$. It is noticeable that we find a mean value approximately of $0.97 \mathrm{~m}$ when comparing AGQG2017 with altimetry data, which is due to the applied zero-order term in computing AGQG2017, and we remove this value for model comparison. The validation results are shown in Figure 9 and Table 2, and the SD of the misfit between altimeter-derived quasi-geoid heights and gravimetric quasi-geoid decreases from 0.028 to $0.023 \mathrm{~m}$, when validating QGland_TS and QGland_TSA, respectively. Moreover, the combination of airborne data reduces the $\mathrm{max} / \mathrm{min}$ value of the misfit between the altimeter-derived data and gravimetric quasi-geoid, by a magnitude of several centimetres, see Table 2. Figure 9 shows that the incorporation of airborne data prominently improves the quasi-geoid in coastal areas, especially in areas around $\left(147.5^{\circ} \mathrm{E}, 38.2^{\circ} \mathrm{S}\right)$ and $\left(147.6^{\circ} \mathrm{E}, 38.5^{\circ} \mathrm{S}\right)$, which is in line with the contribution of airborne data to local gravimetric quasi-geoid.

The validation results show that the recent altimetry data can be potentially used to validate the high-frequency signals introduced by airborne data. Moreover, these altimetry data can be used to distinguish the qualities of different models, which may be beneficial for coast gravity field model assessment, especially in regions lack of control data. These results also demonstrate that the combination of airborne data improves the coastal gravity field, which is consistent with the previous study, e.g. see Hwang et al. (2006). However, we observe undesirable edge effects that affect the quality of QGland_TSA, see the red signals around $\left(148.0^{\circ} \mathrm{E}, 38.3^{\circ} \mathrm{S}\right)$ and $\left(148.2^{\circ} \mathrm{E}, 38.0^{\circ} \mathrm{S}\right)$ in Figure 9 (a). This demonstrates the quality of solution computed with airborne gravity data may become less reliable close to the edge of airborne survey, even we used DWC for merging heterogeneous data at various altitudes to derive the data with a uniform resolution.

The comparisons with other existing models show that QGland_TSA is of highest quality. QGland_TS, AGQG2017, and EGM2008 have comparable accuracies, and all these three models are worse than QGland_TSA, by the magnitudes of approximately $5 \sim 8 \mathrm{~mm}$. We introduce the propagated error information of EGM2008 and AGQG2017 (see Figure 10) for validation. The EGM2008 commission errors are composed of low- and high-degree errors. The low-degree ones were estimated using a satellite-only model through error propagation, while the high-degree errors were computed through a surface integral formula using the calibrated gravity anomalies (Pavlis et al. 2012). The error information of AGQG2017 was computed by using the EGM2008 commission errors and estimated errors of ground-based gravity data (Featherstone et al. 2018a). As shown in Figure 9 (a) and (c), the comparison between QGland_TSA and AGQG2017 shows the former is particularly better in coastal areas, e.g. in regions around $\left(147.4^{\circ} \mathrm{E}, 38.3^{\circ}\right.$ S) and $\left(147.1^{\circ} \mathrm{E}, 38.6^{\circ} \mathrm{S}\right)$, where larger misfit between the altimeter-derived quasi-geoid heights and AGQG2017 are observed. The associated errors of AGQG2017 range from 4.2 to $5.9 \mathrm{~cm}$ in this area, with a mean value of $4.7 \mathrm{~cm}$ (Figure 10 (a)). The validation results show in general agreement with the estimated errors of AGQG2017, where the prominent errors concentrate along the coastline. Different data pre-processing procedures and methods for parameterization partly account for the differences between QGland_TSA and AGQG2017. For instance, QGland_TSA is recovered from Poisson wavelets, while AGQG2017 was computed from a modified Stoke integral. However, the incorporation of airborne data may be the main reason that QGland_TSA outperforms AGQG2017, since AGGA2017 was computed without combining the airborne data in this region. While, the comparison between EGM2008 and QGland_TSA shows that the latter has significant better performances over areas around $\left(147.5^{\circ} \mathrm{E}, 38.5^{\circ} \mathrm{S}\right)$ and $\left(147.7^{\circ} \mathrm{E}\right.$, $\left.38.3^{\circ} \mathrm{S}\right)$. The associated errors of EGM2008 range from 4.3 to $6.4 \mathrm{~cm}$, with a mean value of $4.9 \mathrm{~cm}$. The 
validation results of EGM2008 using altimeter-derived quasi-geoid heights agree with the estimated errors of EGM2008 (Figure 10 (b)), where the significant errors are observed along coastal regions. The combination of local airborne gravity data significantly reduces these errors in coastal zones. Similarly, the difference between QGland_TSA and EGM2008 is mainly attributed to the different modelling techniques and the additional signals introduced from the incorporation of recently surveyed ground-based data and airborne measurements.

The accuracies of EIGEN-6C4, GECO, and SGG-UGM-1 are between 3.4 and $3.7 \mathrm{~cm}$, all of which are worse than the four models discussed above. EIGEN-6C4 shows prominent discrepancies with the altimeterderived data over the coastal areas. The results derived from GECO and SGG-UGM-1 show similar patterns, where large errors occur at south of $38.4^{\circ} \mathrm{S}$. We notice that the mean bias between EIGEN-6C4 and altimeterderived quasi-geoid heights is approximately $10 \mathrm{~cm}$, while we do not observe this bias from the comparisons with EGM2008 or models developed with EGM2008 (i.e., QGland_TSA, QGland_TS, AGQG2017, GECO, and SGG-UGM-1). Possible reason may be due to the selection of reference model in altimeter data pre-processing, where we use EGM2008 as the reference model. Consequently, the computed altimeter-derived data may show more similar properties as EGM2008 than as EIGEN-6C4. Those developed by combining GOCE data and EGM2008 (i.e., GECO and SGG-UGM-1) do not demonstrate comparable performances as EGM2008 alone. This is particularly prominent in the southwest parts, see Figure 9 (e) and (f). The accuracies of GECO and SGG-UGM-1 decrease by 0.8 and $0.5 \mathrm{~cm}$, respectively, compared with EGM2008. GOCO05c is of worst quality, and its accuracy decreases to $4.8 \mathrm{~cm}$. 

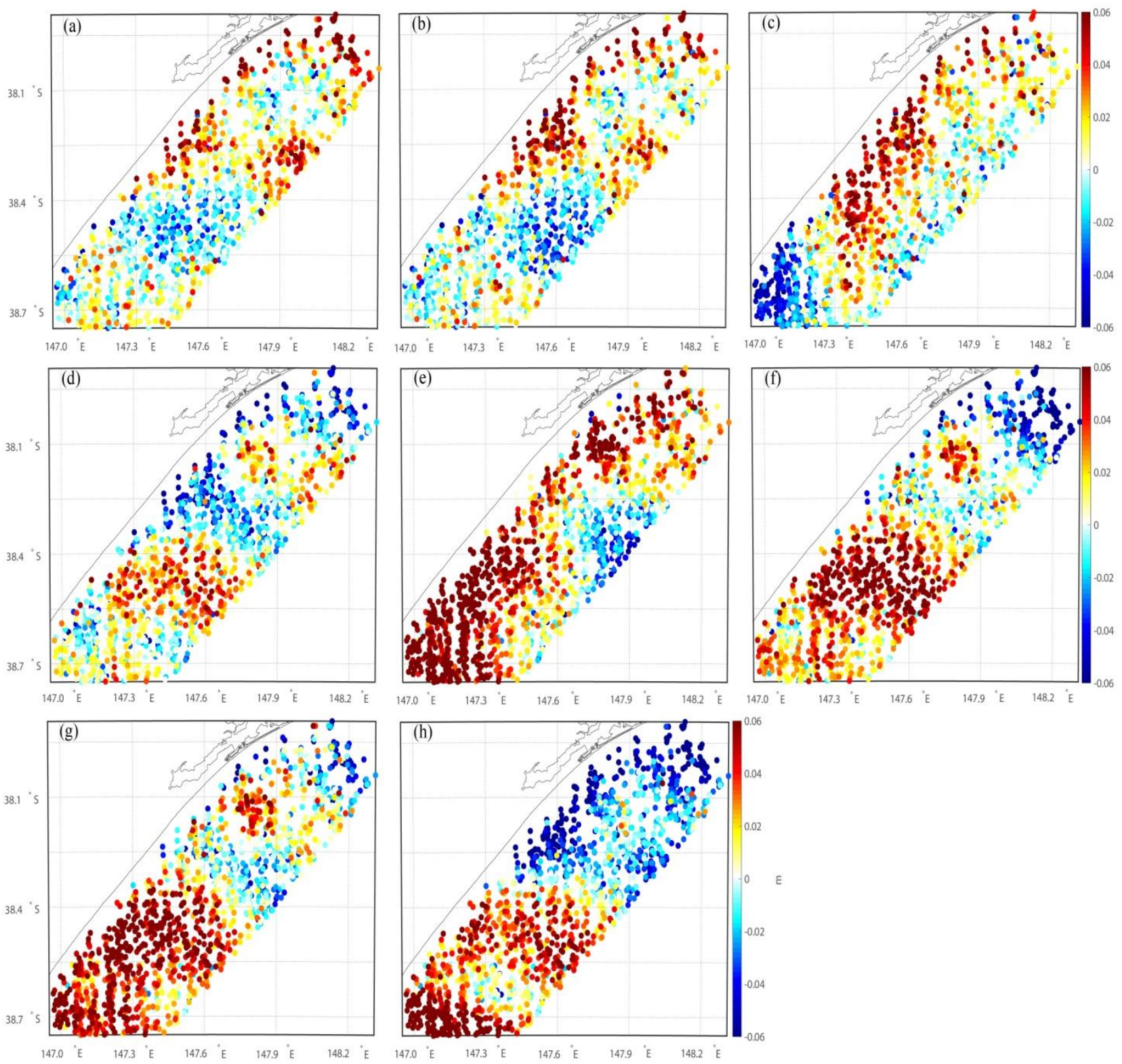

Figure 9 Evaluations of different gravimetric quasi-geoid models with the altimeter-derived quasi-geoid heights only located within the boundary of airborne survey. (a) QGland_TSA, (b) QGland_TS, (c) AGQG2017, (d) EGM2008, (e) EIGEN-6C4, (f) GECO, (g) SGG-UGM-1, (h) GOCO05c. Note that the mean values of the misfit between gravimetric quasi-geoid models and altimeter-derived data are removed Table 2 Statistics of validations of different gravimetric quasi-geoids with the altimeter-derived quasi-geoid heights (units: m). Note that the mean values of the misfit between gravimetric quasi-geoid models and altimeter-derived data are removed

\begin{tabular}{llll}
\hline & Max & Min & SD \\
\hline QGland_TSA & 0.136 & -0.169 & 0.023 \\
QGland_TS & 0.163 & -0.189 & 0.028 \\
AGQG2017 & 0.148 & -0.179 & 0.031 \\
EGM2008 & 0.171 & -0.165 & 0.029 \\
EIGEN-6C4 & 0.214 & -0.127 & 0.037 \\
GECO & 0.150 & -0.157 & 0.037 \\
SGG-UGM-1 & 0.178 & -0.138 & 0.034 \\
GOCO05c & 0.155 & -0.194 & 0.048 \\
\hline
\end{tabular}




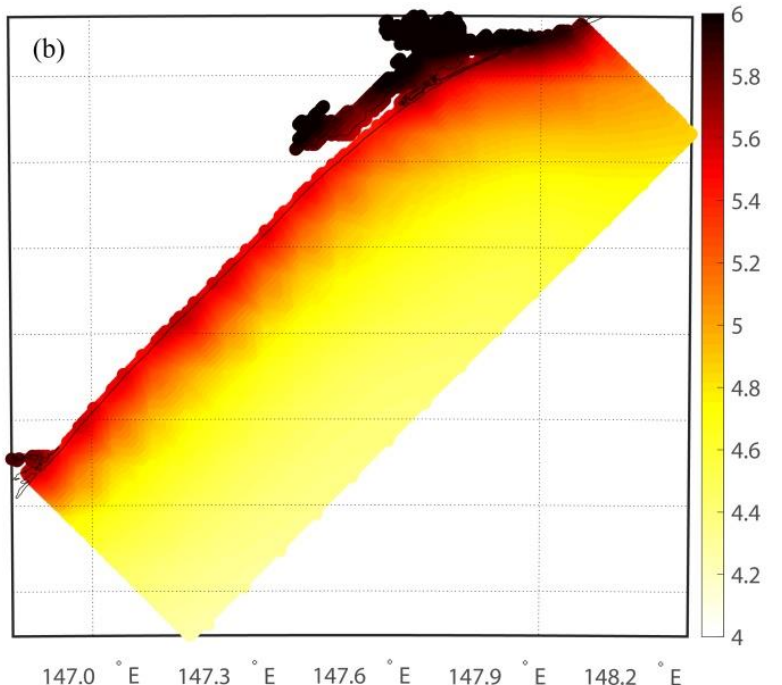

Figure 10 Associated errors of (a) AGQG2017 and (b) EGM2008

\subsection{Coastal mean dynamic topography determination}

Further, we investigate the possibility to improve the coastal MDT using the quasi-geoid computed with airborne gravity data. The geodetic MDT is computed as the difference between mean sea surface (MSS) and geoid/quasi-geoid. The DTU15MSS is chosen as the MSS, provided as the gridded data with a spatial resolution of 1' $\times 1^{\prime}$ (Andersen et al. 2015). Considering that QGland_TSA, QGland_TS, AGQG2017 and EGM2008 have better performances than other models when validated against the altimeter-derived data, we compute local MDTs based on these four models. We notice that the gridded gravity data for computing QGland_TSA, QGland_TS, and AGQG2017 have the spatial resolutions of $1^{\prime} \times 1^{\prime}$, which are consistent with the resolution of DTU15MSS. Moreover, considering that the application of dedicated filtering to smooth the raw MDT may be not entirely satisfactory because of the unclear loss of signals (e.g. Becker et al. 2014), we do not apply the filtering procedure and the raw MDTs are used for comparison.

The MDTs computed based on QGland_TSA, QGland_TS, AGQG2017 and EGM2008 are denoted as MDTQGland_TSA, MDTQGland_TS, MDTQGland_AGQG2017, and MDTQGland_EGM2008, respectively, see Figure 11. These MDTs show similar patterns over the Gippsland Basin, although observable differences appear among different MDTs, especially in the northern parts. However, because of the lack of in-situ observations, the accuracies of different MDTs cannot be quantified. These MDTs show considerably smooth patterns in most areas, indicate the small change of local sea surface topography. However, extreme values are observable along the coastal areas, see these features like mass blocks in Figure 11. These values are typically identified as errors due to the poorly modelled coastal quasi-geoid and uncorrected errors in the MSS, e.g. see Hipkin et al. (2004) and Wu et al. (2017b). These extreme values are nearly unchanged even when the airborne data are used for coastal quasi-geoid improvement. Thus, the computed MDTs may significantly suffer from the uncorrected errors in the adopted MSS, especially in regions close to coast (Andersen et al. 2010; Andersen and Scharroo 2011). The errors in MDTs are generally consistent with the DTU15MSS error information shown in Figure 12, where significant errors concentrate along the coast and reach the magnitude of several centimetres. It is noticeable the displayed DTU15MSS error in Figure 12 is only the interpolation error and cannot be regarded as the formally propagated error, and the actual MSS error is likely larger than the interpolation error (e.g. Andersen and Knudsen 2009).

It is noticeable that the altimeter-derived data in Section 2.3 may be used for refining the coastal geodetic MDT. In fact, the incorporation of recent altimeter data may improve the consistency between coastal MDT and 
tide gauge-derived MDT data and ocean MDT (Ophaug et al. 2015; Idžanović et al. 2017). However, the altimeter-derived data that are very close to coast were screened out since the waveforms of these data are highly contaminated. As a result, data gaps exist close the coastal lines, see Figure 2. Thus, the altimeter-derived data in Section 2.3 cannot be directly used for MDT refinement over the regions that are close to coastlines. Moreover, due to the limited resolutions of these recent altimeter data, these data alone may be not enough for highresolution MDT determination.
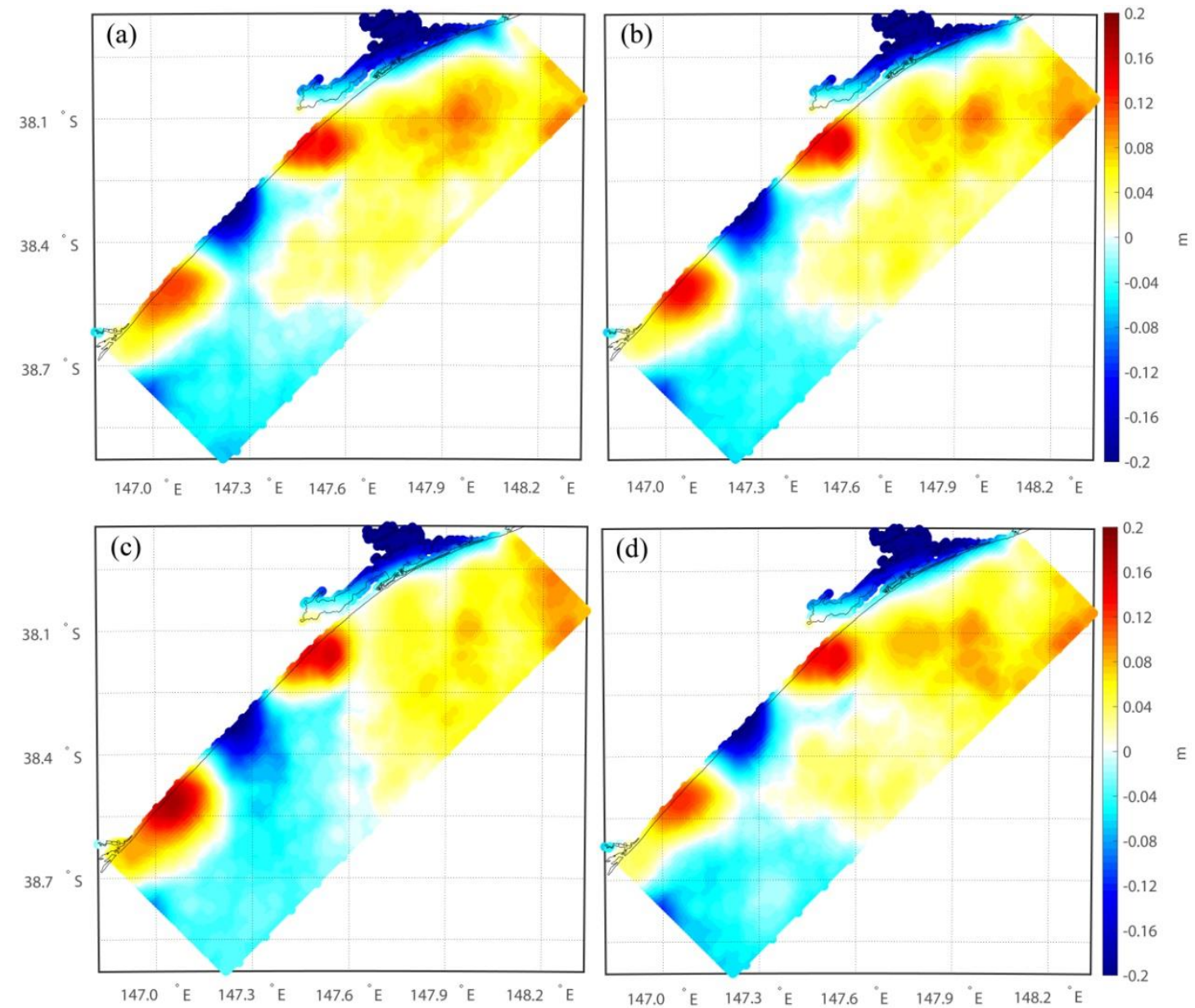

Figure 11 Geodetic MDTs determination over the Gippsland Basin. (a) MDTQGland_TSA, (b) MDTQGland_TS, (c) MDTQGland_AGQG2017, and (d) MDTQGland_EGM2008. For all profiles, the mean values are removed

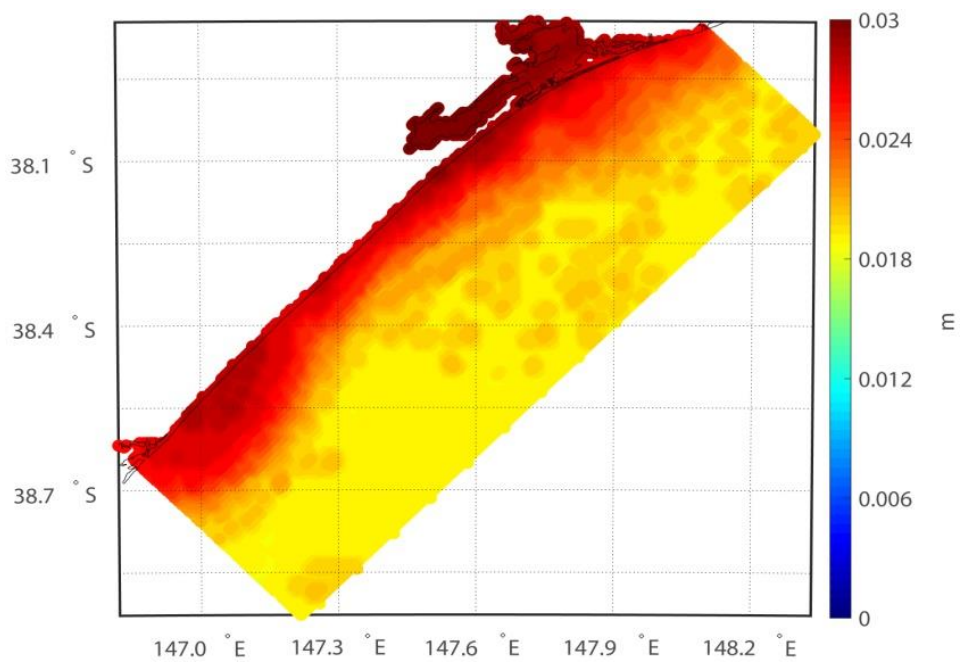

Figure 12 The interpolation error of DTU15MSS 


\section{Conclusions}

We investigate the role of airborne gravity data in coastal gravity field modelling, in particular, the possibility of validating the coastal quasi-geoid/geoid through the recent altimetry data (CryoSat-2, Jason-1, and SARAL/ Altika) is investigated. Moreover, we combine airborne gravimetric measurements and heterogeneous ground-based gravity data for regional refinement, and quantify and validate the contribution introduced by airborne data.

A coastal region in the Gippsland Basin over the south-eastern coast of Australia is chosen as a case study, where a high-resolution airborne gravimetric survey that covers both onshore and offshore areas is available. Numerical experiments show that the effects introduced by airborne gravity data display as small-scale patterns on the centimetre scale in terms of quasi-geoid heights, which mainly locate along the coastal areas. Evaluation of the model computed with airborne measurements using local GPS/levelling data can hardly detect the high-frequency signals introduced by airborne data, due to the sparsely distribution of local GPS/levelling data. On the other hand, the validations of different models against the recent altimeter-derived quasi geoid heights demonstrate that the incorporation of airborne data improve the local quasi-geoid in coastal areas, compared with the one derived from ground-based data alone. By combining airborne data for modelling, the SD of the misfit between the altimeter-derived data and modelled gravimetric quasi-geoid decreases from 2.8 to $2.3 \mathrm{~cm}$. These results indicate that the recent altimeter data may be useful for gravity field model assessment in coastal areas, especially in regions lack of control data. Further comparisons with the existing models show that the solution computed by merging airborne, terrestrial and altimetry gravity data is of highest quality, which indicate that the combination of airborne gravity data improves coastal gravity field.

The computed geodetic MDTs based on different gravimetric quasi-geoids demonstrate that errors are still prominent along the coastal areas, even when airborne data are incorporated for local quasi-geoid refinement. This indicates that local coastal MDTs may substantially suffer from the errors in the MSS. Thus, the further work involves for coastal MSS refinement by incorporating recent altimeter data and other data sources (e.g., the mean sea level records derived from tide gauge observations).

\section{A nlzmomolodomanta}

The authors would like to give sincerest thanks to the three anomalous reviewers for the beneficial suggestions and comments, which are of great value for improving the manuscript. The authors also thank Associate Editor for their kind assistances and constructive comments. Thanks to Prof. Roland Klees and Dr Cornelis Slobbe from Delft University of Technology for kindly providing their original software. We gratefully acknowledge the CarbonNet Project Airborne Gravity Survey over Gippsland contracted by Department of Primary Industries of Victoria State in Australia. This study was supported by the Natural Science Foundation of Jiangsu Province, China (No. BK20190498), the Fundamental Research Funds for the Central Universities (No. 2018B07314), the State Scholarship Fund from Chinese Scholarship Council (No. 201306270014), the National Natural Science Foundation of China (No. 41830110, 41931074), the Open Research Fund Program of Key Laboratory of Geodesy and Earth's Dynamics (No. SKLGED2018-1-2-E), and the Key Laboratory of Geospace Environment and Geodesy, Ministry of Education, Wuhan University (No. 17-01-09).

\section{Author contributions}

All the authors have contributed to designing the study and writing the manuscript. YW and AA initiated the study, designed the numerical experiments and wrote the manuscript. WF, JM, and OA provided the data supplied beneficial suggestions. YW finalized the manuscript. All authors read and approved the final manuscript.

\section{Compliance with ethical standards}


Conflict of interest The authors declare that they have no competing interests.

\section{Data availability}

The airborne gravity data are assessed from

http://earthresources.vic.gov.au/earth-resources/victorias-earth-resources/carbon-storage/about-carbon-capture-an d-storage/archive/About-the-CarbonNet-Project/airborne-gravity-survey. Altimetric gravity anomalies were computed by the Scripps Institution of Oceanography, which are available at http://topex.ucsd.edu/ marine_grav/mar_grav.html. Altimetry data for gravity field model assessment were obtained from Radar Altimeter Database System (RADS) and are freely available through http://rads.tudelft.nl/rads/rads.shtml. AGQG2017 and its error information are available at https://s3-ap-southeast-2.amazonaws.com/geoid/. EGM2008

and its associated error grid are from https://earth-info.nga.mil/GandG/wgs84/gravitymod/egm2008/egm08_wgs84.html,_ while other global geopotential models can be publicly accessed from http://icgem.gfz-potsdam.de/home. DTU15MSS and its associated error grid are available on https://ftp.space.dtu.dk/pub/DTU15/1_MIN/.

\section{References}

Abulaitijiang A, Andersen OB, Stenseng L (2015) Coastal sea level from inland CryoSat-2 interferometric SAR altimetry. Geophys Res Lett 42(6):1841-1847. https://doi.org/10.1002/2015GL063131

Amos MJ, Featherstone WE (2004) A comparison of gridding techniques for terrestrial gravity observations in New Zealand. Proceedings of Gravity, Geoid and Space Missions Symposium 2004, Porto, Portugal

Andersen OB, Knudsen P (2000) The role of satellite altimetry in gravity field modelling in coastal areas. Phys Chem Earth 25(1):17-24. https://doi.org/10.1016/S1464-1895(00)00004-1

Andersen OB, Knudsen P (2009) DNSC08 mean sea surface and mean dynamic topography models. Journal of Geophysical Research 114:C11001. https://doi.org/10.1029/2008JC005179

Andersen OB, Scharroo R (2011) Range and geophysical corrections in coastal regions: and implications for mean sea surface determination. In: Vignudelli et al (eds) Coastal altimetry, Springer, Berlin, Heidelberg

Andersen OB, Knudsen P, Berry, PAM, Kenyon S, Trimmer R (2010) Recent developments in high-resolution global gravity field modeling. The leading edge 29(5):540-545. https://doi.org/10.1190/1.3422451

Andersen OB, Piccioni G, Knudsen P, Stenseng L (2015) The DTU15 Mean Sea Surface and Mean Dynamic Topography - focusing on Arctic issues and development. In: OSTST Meeting, Reston, USA

Andersen OB, Nielsen K, Knudsen P, Hughes CW, Bingham R, Fenoglio-Marc L, Gravelle M, Kern M, Polo SP (2018) Improving the coastal mean dynamic topography by geodetic combination of tide gauge and satellite altimetry. Mar Geod 41(6):517-545. https://doi.org/10.1080/01490419.2018.1530320

Barzaghi R, Borghi A, Keller K, Forsberg R, Giori I, Loretti I, Olesen AV, Stenseng L (2009) Airborne gravity

tests in the Italian area to improve the geoid model of Italy. Geophys Prospect 57(4):625-632. https://doi.org/10.1111/j.1365-2478.2008.00776.x

Bastos L, Cunha S, Forsberg R, Olesen A, Gidskehaug A, Timmen L, Meyer U (2000) On the use of airborne gravimetry in gravity field modelling: experiences from the AGMASCO project. Phys Chem Earth 25(1):1-7. https://doi.org/10.1016/S1464-1895(00)00004-1

Becker S, Brockmann JM, Schuh WD (2014) Mean dynamic topography estimates purely based on GOCE gravity field models and altimetry. Geophys Res Lett 41(6):2063-2069. https://doi.org/10.1002/2014GL059510

Bentel K, Schmidt M, Rolstad DC (2013) Artifacts in regional gravity representations with spherical radial basis functions. Journal of Geodetic Science 3(3):173-187. https://doi.org/10.2478/jogs-2013-0029

Bonnefond P, Laurain O, Exertier P, Boy F, Guinle T, Picot N, Labroue S, Raynal M, Donlon C, Féménias P, 
Parrinello T, Dinardo S (2018) Calibrating the SAR SSH of Sentinel-3A and CryoSat-2 over the Corsica Facilities. Remote Sensing 10(1):92. https://doi.org/10.3390/rs10010092

Brown G (1977) The average impulse responce of a rough surface and its applications. IEEE J Oceanic Eng 2(1):67-74. https://doi.org/10.1109/JOE.1977.1145328

Chambodut A, Panet I, Mandea M, Diament M, Holschneider M, Jamet O (2005) Wavelet frames: an alternative to spherical harmonic representation of potential fields. Geophys J Int 163(3):875-899. https://doi.org/10.1111/j.1365-246X.2005.02754.x

Cipollini P, Beneviste J, Bouffard J, Emery W, Fenoglio-Marc L, Gommenginger C, Griffin D, Hoyer J, Kurapov A, Madsen K, Mercier F, Miller L, Pascual A, Ravichandran M, Shillington F, Snaith H, Strub, T, Vandemark D, Vignudelli S, Wilkin J, Woodworth P, Zavala-Garay J (2010) The role of altimetry in coastal observing systems. In: Hall, J.; Harrison, D.E.; Stammer, D., (eds.) Proceedings of OceanObs'09: Sustained Ocean Observations and Information for Society, vol. 2, European Space Agency, WPP-306, pp. 181-191, https://doi.org/ 10.5270/OceanObs09.cwp.16

Claessens SJ (2012) Evaluation of Gravity and Altimetry Data in Australian Coastal Regions. In: Kenyon S., Pacino M., Marti U. (eds) Geodesy for Planet Earth. International Association of Geodesy Symposia, Springer, Berlin, Heidelberg, 136:435-442. https://doi.org/10.1007/ 978-3-642-20338-1_52.

Deng X, Featherstone WE (2006) A coastal retracking system for satellite radar altimeter waveforms: Application to ERS2 around Australia. J Geophys Res Oceans 111(C06012). https://doi.org/ 10.1029/2005JC003039

Dunn JR, Ridgway KR (2002) Mapping ocean properties in regions of complex topography. Deep Sea Research 49(3):591-604. https://doi.org/10.1016/S0967-0637(01)00069-3

Featherstone WE (2009) Only use ship-track gravity data with caution: a case-study around Australia. Aust J Earth Sci 56(2):191-195. https://doi.org/10.1080/08120090802547025

Featherstone WE (2010) Satellite and airborne gravimetry: their role in geoid determination and some suggestions. In: Airborne Gravity 2010, ed. Lane, R., Geoscience Australia, Canberra

Featherstone WE, Filmer MS (2012) The north-south tilt in the Australian Height Datum is explained by the ocean's mean dynamic topography. J Geophys Res Oceans 117(C8): C08035. https://doi.org/ 10.1029/2012JC007974

Featherstone WE, Kirby JF, Hirt C, Filmer MS, Claessens SJ, Brown NJ, Hu G, Johnston GM (2011) The AUSGeoid09 model of the Australian Height Datum. J Geod 85(3):133-150. https://doi.org/10.1007/ s00190-010-0422-2

Featherstone WE, McCubbine JC, Brown NJ, Claessens SJ, Filmer MS, Kirby JF (2018a) The first Australian gravimetric quasigeoid model with location-specific uncertainty estimates. J Geod 92(2):149-168. https://doi.org/ 10.1007/s00190-017-1053-7

Featherstone WE, Brown NJ, McCubbine JC, Filmer MS (2018b) Description and release of Australian gravity field model testing data. Aust J Earth Sci 65(3):1-7. https://doi.org/10.1080/08120099.2018.1412353

Fecher T, Pail R, Gruber T (2017) GOCO05c: A new combined gravity field model based on full normal equations and regionally varying weighting. Surv Geophys 38(3):571-590. https://doi.org/ 10.1007/s10712-016-9406-y.

Fernandes MJ, Bastos L, Forsberg R, Olesen A, Leite F (2000) Geoid modelling In coastal regions using airborne and satellite data: Case study in the Azores. In: Schwarz KP. (eds) Geodesy Beyond 2000. International Association of Geodesy Symposia, vol 121, Springer, Berlin, Heidelberg, pp. 112-117, https://doi.org/10.1007/978-3-642-59742-8_18

Filmer MS, Featherstone WE (2012) A re-evaluation of the offset in the Australian Height Datum between mainland Australia and Tasmania. Mar Geod 35(1):107-119. https://doi.org/10.1080/01490419.2011.634961

Filmer MS, Hughes CW, Woodworth PL, Featherstone WE, Bingham RJ (2018) Comparisons between geodetic and oceanographic approaches to estimate mean dynamic topography for vertical datum unification: 
evaluation at Australia tide gauge. J Geod 92(12):1413-1437. https://doi.org/ 0.1007/s00190-018-1131-5

Forsberg R (1984) A study of terrain reductions, density anomalies and geophysical inversion methods in gravity field modelling. Report No. 355, Department of Geodetic Science and Surveying, The Ohio State University, Colombus, Ohio, USA

Forsberg R (1987) A new covariance model for inertial gravimetry and gradiometry. J Geophys Res 92(B2):1305-1310. https://doi.org/10.1029/JB092iB02p01305

Forsberg R (2002) Downward continuation of airborne gravity-an Arctic case story. In: Proceedings of the international gravity and geoid commission meeting, Thessaloniki

Forsberg R, Kenyon S (1995) Downward continuation of airborne gravity data. Proceedings of the IAG Symposium on Airborne Gravity Field Determination, Report 60010, Department of Geomatics Engineering, University of Calgary, Canada, pp. 73-80

Forsberg R, Tscherning CC (1981) The use of height data in gravity field approximation by collocation. J Geophys Res Solid Earth 86(B9):7843-7854. https://doi.org/10.1029/JB086iB09p07843

Forsberg R, Olesen A, Bastos L, Gidskehaug A, Meyer U, Timmen L (2000) Airborne geoid determination. Earth Planets Space 52(10):863-866. https://doi.org/10.1186/BF03352296

Forsberg R, Olesen A, Keller K, Møller M, Gidskehaug A, Solheim D (2001) Airborne gravity and geoid surveys in the arctic and baltic seas. In: Proceedings of international symposium on kinematic systems in geodesy, geomatics and navigation (KIS-2001), Banff, pp. 586-593

Forsberg R, Olesen AV, Alshamsi A, Gidskehaug A, Ses S, Kadir M, Peter B (2012a) Airborne gravimetry survey for the marine area of the United Arab Emirates. Mar Geod 35(3):221-232. https://doi.org/10.1080/01490419.2012.672874

Forsberg R, Ses S, Alshamsi A, Hassan A (2012b) Coastal geoid improvement using airborne gravimetric data in the United Arab Emirates. Int J Phys Sc 7(45):6012-6023. https://doi.org/ 10.5897/IJPS12.413

Förste C, Bruinsma SL, Abrikosov O, Lemoine JM, Schaller T, Götze HJ, Ebbing J, Marty JC, Flechtner F, Balmino R, Biancale R (2014) EIGEN-6C4 The latest combined global gravity field model including GOCE data up to degree and order 2190 of GFZ Potsdam and GRGS Toulouse. The 5th GOCE User Workshop, Paris, France

Garcia ES, Sandwell DT, Smith, WHF (2014) Retracking CryoSat-2, Envisat and Jason-1 radar altimetry waveforms for improved gravity field recovery. Geophys J Int 196(3):1402-1422. https://doi.org/ $10.1093 / \mathrm{gji} / \mathrm{ggt} 469$

Gilardoni M, Reguzzoni M, Sampietro D (2015) GECO: a global gravity model by locally combining GOCE data and EGM2008. Stud Geophys Geod 60(2):228-247. doi.org/10.1007/s11200-015-1114-14

Heck B, Seitz K (2007) A comparison of the tesseroid, prism and point-mass approaches for mass reductions in gravity field modelling. J Geod 81(2):121-136. https://doi.org/10.1007/s00190-006-0094-0

Hipkin RG, Haines K, Beggan C, Bingley R, Hernandez F, Holt J, Baker T (2004) The geoid EDIN2000 and mean sea surface topography around the British Isles. Geophys J Int 157(2):565-577. https://doi.org/10.1111/j.1365-246X.2004.01989.x

Hirt C (2010) Prediction of vertical deflections from high-degree spherical harmonic synthesis and residual terrain model data. J Geod 84(3):179-190. https://doi.org/ 10.1007/s00190-009-0354-x

Hirt C (2013) RTM gravity forward-modelling using topography/bathymetry data to improve high-degree global geopotential models in the coastal zone. Mar Geod 36(2):1-20. https://doi.org/ 10.1080/01490419.2013.779334

Holschneider M, Iglewska-Nowak I (2007) Poisson wavelets on the sphere. J Fourier Anal Appl 13(4):405-419. https://doi.org/10.1007/s00041-006-6909-9

Holschneider M, Chambodut A, Mandea M (2003) From global to regional analysis of the magnetic field on the 
sphere using wavelet frames. Phys Earth Planet In 135(2-3):107-124. https://doi.org/ $10.1016 / \mathrm{S} 0031-9201(02) 00210-8$

Huang, J (2017) Determining coastal mean dynamic topography by geodetic methods. Geophys Res Lett 44(21): 11125-11128. https://doi.org/10.1002/2017GL076020

Hwang C, Guo J, Deng X, Hsu HY, Liu Y (2006) Coastal gravity anomalies from retracked Geosat/GM altimetry: improvement, limitation and the role of airborne gravity data. J Geod 80(4):204-216. https://doi.org/ 10.1007/s00190-006-0052-x

Idžanović M, Ophaug V, Andersen OB (2017) The coastal mean dynamic topography in Norway observed by CryoSat-2 and GOCE. Geophys Res Lett 44(11):5609-5617. https://doi.org/10.1002/ 2017GL073777

Jekeli C, Yang HJ, Kwon JH (2013) Geoid determination in South Korea from a combination of terrestrial and airborne gravity anomaly data. Journal of the Korean Society of Surveying, Geodesy, Photogrammetry and Cartography 31(6):567-576. https://doi.org/ 10.7848/ksgpc.2013.31.6-2.567

Kearsley AHW, Forsberg R, Olesen A, Bastos L, Hehl K, Meyer U, Gidskehaug A (1998) Airborne gravimetry used in precise geoid computations by ring integration. $J$ Geod 72(10):600-605. https://doi.org/10.1007/s001900050198

Klees R, Tenzer R, Prutkin I, Wittwer T (2008) A data-driven approach to local gravity field modelling using spherical radial basis functions. J Geod 82(8):457-471. https://doi.org/10.1007/s00190-007-0196-3

Koch KR, Kusche J (2002) Regularization of geopotential determination from satellite data by variance components. J Geod 76(5):259-268. https://doi.org/10.1007/s00190-002-0245-x

Kusche J (2003) A Monte-Carlo technique for weight estimation in satellite geodesy. J Geod 76(11):641-652. https://doi.org/10.1007/s00190-002-0302-5

Kusche J, Klees R (2002) Regularization of gravity field estimation from satellite gravity gradients. J Geod 76(6): 359-368. https://doi.org/10.1007/s00190-002-0257-6

Liang W, Xu X, Li J, Zhu G (2018) The determination of an ultra-high gravity field model SGG-UGM-1 by combining EGM2008 gravity anomaly and GOCE observation data. Acta Geodaetica et Cartographica Sinica 47(4):425-434. https://doi.org/10.11947/j.AGCS.2018.20170269

Lieb V, Schmidt M, Dettmering D, Börger K (2016) Combination of various observation techniques for regional modeling of the gravity field. J Geophys Res Solid Earth 121:3825-3845, https://doi:10.1002/2015JB012586

Martin B, Oteng M, Stefan E (2011) CarbonNet project airborne gravity survey Gippsland Basin, Victoria, Austraila 2011 for Victoria State Government Department of Primary industries. Technical report

McCubbine JC, Amos MJ, Tontini FC, Smith E, Winefied R, Stagpoole V, Featherstone WE (2018) The New Zealand gravimetric quasigeoid model 2017 that incorporates nationwide airborne gravimetry. J Geod 92(8): 923-937. https://doi.org/ 10.1007/s00190-017-1103-1

Olesen AV (2003) Improved airborne scalar gravimetry for regional gravity field mapping and geoid determination. Ph.D. thesis, University of Copenhagen, Denmark

Olesen AV, Forsberg R, Kearsley AHW (2000) Great Barrier Reef airborne gravity survey (BRAGS'99). A gravity survey piggybacked on a bathymetry mission. In: Sideris, M. G. (ed.), Gravity, Geoid and Geodynamics 2000, International Association of Geodesy Symposia, 123, Springer, Berlin, pp. 247-251, https://doi.org/10.1007/978-3-662-04827-6_41

Olesen AV, Andersen OB, Tscherning CC (2002) Merging of airborne gravity and gravity derived from satellite altimetry: test cases along the coast of Greenland. Stud Geophys Geod 46(3):387-394. https://doi.org/10.1023/A:1019577232253

Omang OCD, Forsberg R (2000) How to handle topography in practical geoid determination: three examples. J Geod 74(6):458-466. https://doi.org/10.1007/s001900000107

Ophaug V, Breili K, Gerlach C (2015) A comparative assessment of coastal mean dynamic topography in Norway 
by geodetic and ocean approaches. J Geophys Res Oceans, 120(12):7807-7826. https://doi.org/10.1002/2015JC011145

Panet I, Kuroishi Y, Holschneider M (2011) Wavelet modelling of the gravity field by domain decomposition methods: an example over Japan. Geophys J Int 184(1):203-219. https://doi.org/10.1111/j.1365-246X.2010.04840.x

Passaro M, Dinardo S, Quartly GD, Snaith HM, Benvenist, J, Cipollini P, Lucash B (2016) Cross-calibrating ALES Envisat and CryoSat-2 Delay-Doppler: a coastal altimetry study in the Indonesian Seas. Adv Space Res 58(3):289-303. https://doi.org/10.1016/j.asr.2016.04.011

Pavlis NK, Holmes SA, Kenyon SC, Factor JK (2012) The development and evaluation of Earth Gravitational Model (EGM2008). J Geophys Res Solid Earth 117:B04406. https://doi.org/10.1029/2011JB008916

Pavlis NK, Holmes SA, Kenyon SC, Factor JK (2013) Correction to "The development and evaluation of the Earth Gravitational Model 2008 (EGM2008)”. J Geophys Res Solid Earth 118(5):2633. https://doi.org/ 10.1029/jgrb.50167

Pugh D, Woodworth P (2014) Sea-level science: understanding tides, surges, tsunamis and mean sea-level changes. Cambridge University Press, Cambridge, UK

Ridgway KR, Dunn JR, Wilkin JL (2002) Ocean interpolation by four-dimensional weighted least squares-application to the waters around Australasia. J Atmos Ocean Tech 19(9):1357-1375. https://doi.org/10.1175/1520-0426(2002)019<1357:OIBFDW >2.0.CO;2

Rio MH, Guinehut S, Larnicol G (2011) New CNES-CLS09 global mean dynamic topography computed from the combination of GRACE data, altimetry, and in situ measurements. J Geophys Res Oceans 116:C07018. https://doi.org/10.1029/2010JC006505

Rio MH, Mulet S, Picot N (2014) Beyond GOCE for the ocean circulation estimate: Synergetic use of altimetry, gravimetry, and in situ data provides new insight into geostrophic and Ekman currents. Geophys Res Lett 41(24):8918-8925. https://doi.org/10.1002/2014GL061773

Roelse A, Granger HW, Graham JW (1971) The adjustment of the Australian levelling survey 1970-1971. Technical Report 12, Division of National Mapping, Canberra, Australia

Sandwell DT, Garcia E, Soofi K, Wessel P, Smith WHF (2013) Towards $1 \mathrm{mGal}$ global marine gravity from CryoSat-2, Envisat, and Jason-1. The Leading Edge 32(8):892-899. https://doi.org/10.1190/tle32080892.1

Sandwell DT, Müller RD, Smith WHF, Garcia E, Francis R (2014) New global marine gravity model from CryoSat-2 and Jason-1 reveals buried tectonic structure. Science 346(6205):65-67. https://doi.org/10.1126/science.1258213

Scharroo R, Leuliette EW, Lillibridge JL, Byrne D, Naeije MC, Mitchum GT (2013) RADS: Consistent multi-mission products. In Proc. of the Symposium on 20 Years of Progress in Radar Altimetry, Venice, Italy

Schmidt M, Han SC, Kusche J, Sanchez L Shum CK (2006) Regional high-resolution spatiotemporal gravity modelling from GRACE data using spherical wavelets. Geophys Res Lett 33(8):L08403. https://doi.org/10.1029/2005GL025509

Schwarz KP, Li YC (1996) What can airborne gravimetry contribute to geoid determination?, J Geophys Res Solid Earth 101(8):17873-17881. https://doi.org/10.1029/96JB00819

Sjöberg LE (2005) A discussion on the approximations made in the practical implementation of the remove-compute-restore technique in regional geoid modelling. J Geod 78(11-12):645-653. https://doi.org/10.1007/s00190-004-0430-1

Smith WH (2015) Resolution of seamount geoid anomalies achieved by the SARAL/AltiKa and Envisat RA2 satellite radar altimeters. Mar Geod 38(sup1):644-671. https://doi.org/10.1080/01490419.2015.1014950

Tenzer R, Klees R (2008) The choice of the spherical radial basis functions in local gravity field modelling. Stud Geophys Geod 52(3):287-304. https://doi.org/10.1007/s11200-008-0022-2 
Tracey R, Bacchin M, Wynne P (2007) AAGD07: a new absolute gravity datum for Australian gravity and new standards for the Australian National Gravity Database. ASEG Extended Abstracts, https://doi.org/10. 1071/ASEG2007ab149

Verron J, Sengenes P, Lambin J, Noubel J, Steunou N, Guillot A, Picot N, Coutin-Faye S, Sharma R, Gairola RM, Murthy RD, Richman JG, Griffin D, Pascual A, Rémy F, Gupta PK (2015) The SARAL/AltiKa altimetry satellite mission. Mar Geod 38(SI):2-21. https://doi.org/10.1080/01490419.2014.1000471

Wittwer, T. (2009) Regional gravity field modelling with radial basis functions. Ph.D. thesis, Delft University of Technology, The Netherlands

Woodworth PL, Hughes CW, Bingham RW, Gruber T (2012) Towards worldwide height system unification using ocean information. Journal of Geodetic Science 2(4):302-318. https://doi.org/10.2478/v10156-012- 004-8

Wu Y, Luo Z, Chen W, Chen Y (2017a) High-resolution regional gravity field recovery from Poisson wavelets using heterogeneous observational techniques. Earth Planets Space 69(34):1-15. https://doi.org/10.1186/s40623-017-0618-2

Wu Y, Zhou H, Zhong B, Luo Z (2017b) Regional gravity field recovery using the GOCE gravity gradient tensor and heterogeneous gravimetry and altimetry data. J Geophys Res Solid Earth 122(8):6928-6952. https://doi.org/10.1002/2017JB014196

Wu Y, Zhong B, Luo Z (2018) Investigation of the Tikhonov regularization method in regional gravity field modelling by Poisson wavelets radial basis functions, J Earth Sci-China 29(6):1349-1358. https://doi.org/ 10.1007/s12583-017-0771-3

Zhang S, Sandwell DT (2017) Retracking of SARAL/AltiKa radar altimetry waveforms for optimal gravity field recovery. Mar Geod 40(1):40-56. https://doi.org/10.1080/01490419.2016.1265032 